DOI: http://dx.doi.org/10.18764/2358-4319.v12n1p186-203

\title{
Ensino de Libras em um Curso de Pedagogia por meio da aprendizagem baseada em problemas
}

Marcelo Franco Leão'

Francisca Melo Agapito

\section{RESUMO}

O ensino da Língua Brasileira de Sinais (Libras) passou a ser uma exigência nos cursos de licenciatura no país a partir da promulgação do Decreto № 5.626, sancionado em 2005. Além disso, o contexto atual exige que as aulas no Ensino Superior sejam dinâmicas e envolventes, que estimulem a pesquisa e a autonomia na tomada de decisões, isso para que os futuros profissionais sejam capazes de lidar e solucionar situações reais. Nesse sentido, é preciso que os cursos de licenciatura planejem estratégias diversificadas de ensino para que o estudo de Libras possa promover aprendizagens significativas no decorrer desse processo formativo. Esse estudo teve como objetivo relatar o desenvolvimento de uma metodologia ativa de aprendizagem durante as aulas da disciplina de Libras do Curso de Pedagogia de uma Instituição de Ensino Superior (IES) pública no município de ImperatrizMA. O estudo se configura como exploratório, com abordagem qualitativa e pautada na análise descritiva. Essa experiência pedagógica ocorreu no primeiro semestre de 2017. A estratégia de ensino utilizada foi a aprendizagem baseada em problemas. Os resultados denotaram que, foi perceptível a disposição dos acadêmicos em participar da atividade, a contribuição da mesma para uma construção consistente sobre o conteúdo proposto, assim como refletir sobre a importância da docente buscar a promoção de conhecimentos por meio de estratégias diferenciadas.

Palavras-chave: Prática pedagógica. Estratégias de ensino. Libras.

1 Doutor em Educação e Ensino de Ciências pela Universidade Federal do Rio Grande do Sul. Professor do Instituto Federal do Mato Grosso - Campus Confresa. Participa do Grupo de Pesquisa Ensino de Ciências e Matemática no Baixo Araguaia, registrado no CNPq. Editor da Revista Prática Docente. E-mail:marcelo.leao@cfs.ifmt.edu.br

2 Mestra em Ensino pela Universidade do Vale do Taquari (UNIVATES.) Doutoranda em Ensino (UNIVATES). Professora de Libras da Universidade Federal do Maranhão. E-mail: franciscaagapito@gmail.com 


\title{
Teaching of Libras in a Pedagogy Course through problem-based learning (PBL)
}

\begin{abstract}
The teaching of the Brazilian Sign Language (Libras) became a requirement in undergraduate courses in Brazil since the enactment of Decree No. 5,626, sanctioned in 2005. In addition, the current context requires that classes in Higher Education to be dynamic and that stimulate research and autonomy in decision making, so that future professionals will be able to handle and solve real situations. In this sense, it is necessary that undergraduate courses plan diversified teaching strategies so that the study of Libras can promote meaningful learning in the course of this formative process. This study aimed to report the development of an active learning methodology during classes in the discipline of Libras of the Course of Pedagogy of a Public Institution of Higher Education (IES) in the municipality of ImperatrizMA. The study is exploratory, with a qualitative approach based on the descriptive analysis. This pedagogical experience occurred in the first half of 2017. The teaching strategy used was problem-based learning. In this experience, the students' willingness to participate in the activity, their contribution to a consistent construction of the proposed content, and reflection on the importance of the teacher to seek the promotion of knowledge through differentiated strategies was perceptible.
\end{abstract}

Keywords: Pedagogical practice. Teaching strategies. Libras.

\section{Enseñanza de Libras en un Curso de Pedagogía a través del aprendizaje basado en problemas (ABP)}

\section{RESUMEN}

La enseñanza de la Lengua Brasileña de Señales (Libras) pasó a ser una exigencia en los cursos de licenciatura en el país a partir de la promulgación del Decreto № 5.626, sancionado en 2005. Además, el contexto actual exige que las clases en la Enseñanza Superior sean dinámicas y estimulen la investigación y la autonomía en la toma de decisiones, eso para que los futuros profesionales sean capaces de lidiary solucionar problemas reales. En este sentido, es necesario que los cursos de licenciatura planifiquen estrategias diversificadas de enseñanza para que el estudio de Libras pueda promover aprendizajes significativos 
en el curso de ese proceso formativo. Este estudio tuvo como objetivo relatar el desarrollo de una metodología activa de aprendizaje durante las clases de la disciplina de Libras del Curso de Pedagogía de una Institución de Enseñanza Superior (IES) pública en el municipio de Imperatriz-MA. El estudio se configura como exploratorio, de abordaje cualitativo y pautada en el análisis descriptivo. Esta experiencia pedagógica ocurrió en el primer semestre de 2017. La estrategia de enseñanza utilizada fue el aprendizaje basado en problemas. En esta experiencia fue perceptible la disposición de los académicos en participar de la actividad, la contribución de ésta para una construcción consistente sobre el contenido propuesto, así como reflexionar sobre la importancia de la docente para buscar la promoción de conocimientos a través de estrategias diferenciadas.

Palabras Clave: Práctica pedagógica. Estrategias de enseñanza. Libras.

\section{Introdução}

$\mathrm{Na}$ educação contemporânea, especialmente nos cursos do Ensino Superior, é preciso inovação nas metodologias de ensino para que favoreça a aprendizagem dos acadêmicos em formação (GOBBO; BEBER; BONFIGLIO, 2016). Segundo os autores, as metodologias ativas de aprendizagem podem ser viáveis na formação superior, pois são estratégias em que os alunos utilizam seus saberes e experiências, além da capacidade de articulação e busca de informações, na tentativa de solucionar problemas advindos de atividades que simulam uma situação que requer um posicionamento.

Além disso, comunicar-se de modo eficaz é um desafio para qualquer pessoa na nossa sociedade. Ao reportar-se a pessoa surda o ato de se comunicar torna-se bem mais difícil, haja vista esse grupo social minoritário possui uma singularidade linguística, que é a Libras, uma língua de natureza visual-motora, que uma estrutura gramatical própria, que difere da Língua Portuguesa e que uma parcela significativa da população ouvinte ainda desconhece (BRASIL, 2002).

Por isso, é indubitável que a Libras torne-se objeto de estudo para os futuros professores, visto que, por ser uma língua oficializada somente em 2002 e mais especificamente por ser inserida no currículo da Instituição de Ensino Superior (IES) pesquisada há apenas três (03) anos, carece de estudos mais específicos por parte dos alunos, para que haja 
uma real compreensão sobre seu papel na vida dos surdos. Assim, a utilização de estratégias de ensino podem propiciar uma melhor apreensão e consequentemente um melhor uso dessa aprendizagem quando estes necessitarem.

Outro aspecto a ser considerado, é que o Decreto Federal № 5.626, de 22 de dezembro de 2005, torna obrigatória a inserção da disciplina da Língua Brasileira de Sinais (Libras) no Ensino Superior, especialmente nos cursos de licenciaturas (BRASIL, 2005). O entendimento para tal implementação nas matrizes curriculares da formação inicial de professores se deve ao que a Libras é o meio de comunicação dos surdos, legalmente reconhecida e amplamente utilizada no país.

Em seus estudos, Machado e Lírio (2011) discutiram sobre a importância da disciplina de Libras no currículo do curso de Pedagogia da Universidade Federal do Espírito Santo. Para os autores, esse estudo é importante não somente para os surdos, aos quais é garantida a inclusão na escola e na sociedade, mas sim para capacitar a todos aqueles que atuarão com a educação, dos quais se espera preparação para o atendimento educacional a diferentes públicos e especificidades.

Nesse sentido, a busca por estratégias diversificadas de ensino que possibilitem uma convergência com os conteúdos propostos nessa disciplina podem ser eficazes para a promoção de uma aprendizagem significativa. Considerando esse aspecto, parte-se do princípio de que a mediação dos conhecimentos sobre esta língua deve ser bem conduzidas a fim de propiciar aos futuros professores mais qualificação para atuação profissional. Assim, entrelaçando a perspectiva de formação de futuros educadores e o desenvolvimento de atividades práticas didáticas como mediação dinâmica do processo educativo.

Tomando como base os pressupostos supracitados, o presente artigo tem como objetivo relatar e fazer uma reflexão acerca da utilização de uma estratégia de ensino "Aprendizagem baseada em problemas" e suas implicações para a eficácia da aprendizagem de alunos de um curso de pedagogia de uma Instituição de Ensino Superior (IES) pública no município de Imperatriz-MA.

Essa estratégia de ensino, também conhecida mundialmente por Problem-Based Learning (PBL), já foi objeto de estudo para Ribeiro (2008), ao investigar as contribuições da estratégia para o ensino de engenharia, para Toledo Júnior et al. (2008), que avaliou os resultados obtidos em 21 estudos que utilizaram essa estratégia em cursos médi- 
cos, e para Mezzari (2011), que implementou essa estratégia associada a um ambiente virtual de aprendizagem na disciplina de Parasitologia e Micologia Médica em um curso de medicina, além de outras inúmeras pesquisas sobre o assunto.

Como forma de organização do texto, inicialmente são destacadas algumas considerações pautadas em aportes teóricos que se remetem aos saberes pedagógicos para a prática em sala de aula, sua relevância para uma aprendizagem com resultados positivos. Ademais, é enunciada a relevância da utilização de estratégias e apresentada uma experiência com uma estratégia de ensino que vislumbrasse uma meIhor apreensão do conteúdo proposto, assim como uma maior proatividade dos alunos nesse processo de construção de conhecimentos.

\section{Saberes pedagógicos: Algumas considerações}

A educação, numa visão contemporânea, intima todos os atores envolvidos no processo educativo pensar que tipo de homem busca-se formar para responder as questões políticas, sociais, econômicas e culturais provenientes da realidade brasileira. Para Morin (2004), nesse século de tantas mudanças e concepções, a educação, é vista muito além de um veículo de transmissão de conteúdos.

O maior desafio, segundo o autor supracitado, seria como fazer para que os conteúdos escolares contribuam para a construção de indivíduos mais humanos; que saibam transformar os conteúdos em conhecimentos, tanto para o seu benefício, quanto para a sociedade. Acredita-se que tornar a aprendizagem social, seria o foco desse desafio.

A aprendizagem é um processo que envolve a interligação de ações cognitivas em meio às relações vivenciadas em dado contexto. Segundo o pensamento de Gil (2012), o processo em que conhecimentos, as habilidades, experiências que vão se constituindo no decorrer de situações educativas, a saber, leituras, discussões, aulas, dentre outros, são mecanismos potentes para a efetivação de aprendizagens.

Por compreender que a aprendizagem do indivíduo perpassa pela prática educativa do professor, estes profissionais buscam superar o engessamento de muitas ações arraigadas no cotidiano escolar e propiciar uma educação emancipatória (PIMENTA; ANASTASIOU, 2010).

No ensino superior não é diferente. É salutar considerar que a compreensão de uma "[...] visão mais crítica do ensino, conduzem à 
identificação da necessidade de o professor universitário dotar-se de conhecimento e habilidades de natureza pedagógica" (GIL, 2008, p. 16).

Segundo os estudos de Gobbo, Beber e Bonfiglio (2016), no ensino superior, professores e alunos assumem papéis que estão intimamente ligados, cuja finalidade de suas ações é a construção do conhecimento. Nesse contexto, o professor assume o papel de orientador dos estudos, ou seja, aquele que não fornece respostas prontas, mas que indica caminhos e isso permite que os alunos descubram, por diversos meios, as respostas para seus questionamentos e inquietações, para assim construir sua aprendizagem. Contudo, ainda segundo os autores, é preciso que o aluno tenha pré-disposição em aprender e comprometa-se, de maneira proativa, com o papel de protagonista nesse processo formativo.

Rego (2000), embasando-se nas concepções de teóricos como Piaget e Vygotsky, afirma que na prática pedagógica acontece o processo ensino e aprendizagem, e para que ambos aconteçam de forma significativa, se faz necessário que haja uma inter-relação entre o aluno e o objeto a ser conhecido, sendo o professor formador o mediador do processo educativo.

Para que essa mediação se dê de forma harmoniosa é preciso, segundo Perrenoud (1999) que o professor munido de seus saberes profissionais, possa encontrar condições favoráveis para desenvolver a sua prática, considerando o aluno como ser social, político e cultural, sujeito de sua própria aprendizagem.

Sendo assim, exige-se desse novo professor uma visão holística em relação ao ensino e a aprendizagem. Para tanto, é preciso que este busque uma formação permanente, compreendendo os princípios e saberes necessário a sua prática pedagógica. Para Pimenta e Anastasiou (2010), o saber pedagógico, são os conhecimentos que subsidiam a ação de ensinar. Construções e desconstruções da relação entre a teoria e a prática.

O professor, nessa conjuntura, deve saber usar os saberes, teóricos e práticos em prol da aprendizagem de seus alunos, utilizando-se de uma prática pedagógica consciente e reflexiva. Sabendo antes de tudo exercer o seu papel como agente de transformação, não apenas para superar a ineficiência do ensino escolar, mas para dar significância ao ato de ensinar e aprender. Referente a este aspecto, Candau (2010, p. 13) expõe a necessidade de uma reflexão didática que promova “[...] a busca de práticas pedagógicas que tornem o ensino de fato eficiente [...]". 
Nas palavras de Justino (2013, p. 79) “A prática pedagógica está relacionada à didática utilizada no processo educacional, assim, ela se constitui na relação teoria e prática [...]". A autora acrescenta ainda que um dos principais objetivos da prática pedagógica é "promover situações em que possam ocorrer a observação, a reflexão e a análise de situações-problema apresentadas [...]" (JUSTINO, 2013, p. 78), com o intuito de buscar transformações no contexto em que estão envoltos.

Logo, numa educação contemporânea em que a perspectiva seja a emancipação do ser humano e sua formação profissional, é relevante a construção de conhecimentos mediada por uma prática pedagógica que prime pela reflexão-ação e entrelace os construtos necessários à aprendizagem. Nesse viés, surgem como enfretamento para o conformismo de práticas que se limitam a simplificação do planejamento, as estratégias de ensino que podem potencializar o ato de ensinar e aprender.

\section{O ensino por meio da estratégia "Aprendizagem Baseada em Problemas"}

A maneira de ensinar tem se aperfeiçoado ao longo dos anos. As transformações vividas pela sociedade contemporânea provocam inquietações, reflexões e mudanças nas concepções sobre o processo educativo (MEZZARI, 2011). Por isso, conhecer e explorar diferentes estratégias de ensino é praticamente uma necessidade na atual conjuntura.

Ainda segundo o autor supracitado, para que o processo educativo ocorra de maneira interativa e envolvente, é necessário haver mudanças na maneira em que vem ocorrendo o ensino, tanto em escolas como nas instituições que formam no Ensino Superior. Pela forma tradicional em que esse ensino vem ocorrendo, a construção do conhecimento está centrada no professor, o que compromete a capacidade criativa de pensar e se posicionar do aluno. Em contraposição, o ideal é que ocorra a participação efetiva do aluno nesse processo, o qual o professor precisa planejar de maneira a envolve-lo por meio de atividades que contribua para sua autonomia.

Segundo Mezzari (2011), uma estratégia didático-pedagógica

que pode ser utilizada para atender as demandas educacionais atuais é a Aprendizagem Baseada em Problemas (ABP), ou Problem-Based Learning $(\mathrm{PBL})$, como é mundialmente conhecida. 
Segundo os estudos de Ribeiro (2008), foi no Canadá, mais especificamente Universidade McMaster, por volta dos anos de 1960, que ocorreu a primeira sistematização da PBL, por iniciativa dos administradores e professores da IES. A tentativa foi reverter a situação constatada por meio de pesquisas de que os acadêmicos de medicina concluíam o curso sem as capacidades esperadas para um profissional atuar como convém.

Assim, essa estratégia de ensino está fundamentada, desde sua origem, em princípios educacionais que defendem que a aprendizagem não é um ato passivo, de retenção e memorização de informações (RIBEIRO, 2008). Para o autor, essa estratégia permite formular, construir e até ressignificar conhecimentos e não apenas armazenar informações.

Para Mezzari (2011), essa estratégia utiliza problemas ou simula situações com o objetivo de gerar questionamentos, inquietações cognitivas, desequilíbrios nas concepções existentes, desconforto com o exposto, sensações pelas quais os alunos terão motivações e estímulos para encontrar soluções utilizando sua criatividade.

No entanto, a PBL não pode ser compreendida como meramente uma atividade de pesquisa ou apenas um processo de solucionar problemas, sejam eles teóricos ou experimentais, por meio da aplicação de uma teoria já existente (RIBEIRO, 2008). Mesmo envolvendo também esses elementos, a PBL vai bem além. Nas próprias palavras do autor fica claro esse alerta:

O PBL tampouco é um mero conjunto de técnicas de solução de problemas; apesar de importantes, esta metodologia não pode ser reduzida a elas. Ao contrário, o PBL é uma metodologia de ensino e aprendizagem que utiliza problemas - coerentes para com a futura atuação dos alunos como profissionais e cidadãos - para iniciar, enfocar e motivar a aprendizagem dos conhecimentos conceituais, procedimentais e atitudinais objetivados (RIBEIRO, 2008, p.24).

Assim, a PBL pode ser compreendida como uma estratégia didático-pedagógica centrada no currículo e no aluno, que discute situações-problema em pequenos grupos de aprendizagem, o que facilita o processo de construção de conhecimentos (TOLEDO JÚNIOR et al., 2008).

Segundo os autores supracitados, essa estratégia pode contribuir significativamente para que importantes habilidades sejam desenvolvidas no futuro profissional, tais como: capacidade de comunicação, trabalho colaborativo, busca de informações, iniciativa para solucionar 
problemas, respeito as diversas opiniões, postura crítica e iniciativa para aplicar os conhecimentos construídos em situações práticas.

Além do mais, se o ensino ocorrer de maneira contextualizada, ou seja, utilizando-se de uma situação próxima daquela em que os conhecimentos profissionais serão utilizados, a aprendizagem é favorecida, potencializando, uma melhor apreensão do conteúdo proposto.

No entendimento de Toledo Júnior et al. (2008), a PBL pressupõe estruturar os significados dentro de um contexto específico, o que permite ao aluno defrontar-se com problemas concretos, o que permite desenvolver o pensamento crítico, favorece e amplia o raciocínio estratégico, desenvolve a habilidade de estudo autodirigido, bem como a aplicação dos conhecimentos construídos em contextos próximos aos da futura profissão.

\section{Procedimentos metodológicos}

O presente estudo se configura como exploratório, de abordagem qualitativa e pautada na análise descritiva. De acordo com Medeiros (2014), os estudos exploratórios possuem por finalidade proporcionar ao pesquisador uma familiaridade com o problema, fazendo com que seja ampliado o conhecimento sobre o assunto em discussão.

Segundo Gil (2007), um estudo desse tipo é caracterizado por realizar a descrição de algum fenômeno, fato ou objeto investigado, no qual o levantamento de informações é imprescindível. Referente a abordagem qualitativa, o autor argumentar ser a indicada para pesquisas sociais, nas quais a subjetividade, manifestações e comportamentos não são possíveis de descrever em números.

Com o propósito de se apropriar das contribuições teóricas dos aportes aqui abordados, utilizou-se como experiência com alunos de um curso de Pedagogia de uma Instituição de Ensino Superior (IES) pública no município de Imperatriz-MA. A estratégia de ensino, a "aprendizagem baseada em problemas" no decorrer das aulas da disciplina de Língua Brasileira de Sinais (Libras), no primeiro semestre do ano letivo de 2017.

A disciplina de Libras tornou-se componente curricular obrigatório desde a criação do decreto 5.626/05, que regulamentou a Lei $10.436 / 02$, devendo ser inserida na matriz curricular de todos os cursos de formação de professor, educação especial e fonoaudiologia como objeto de estudo (BRASIL, 2005). 
Por ter em sua composição um caráter teórico e prático, essa disciplina permitiu a elaboração de um planejamento em que se admitiram variações de estratégias didáticas para a prática em sala de aula. Nesse viés apresenta-se o relato e as reflexões da experiência vivenciada em sala de aula com a estratégia "Aprendizagem baseada em problemas".

A prática da estratégia acima mencionada foi realizada em cinco (05) aulas, sendo que, cada aula teve a carga horária de 3h. Estas foram planejadas da seguinte forma: Apresentação de um relato de caso (fictício) que envolvesse algumas das situações reais vivenciadas por surdos na atual sociedade; Divisão dos alunos em dois (02) grupos e discussão de textos diferentes, mas que abordassem sobre a temática "Surdos e a Educação Inclusiva"; Estudo e posterior socialização dos textos com todos os alunos, oportunizando diferentes olhares, conforme cada compreensão; Elaboração da questão problema; Construção de texto dissertativo em conformidade com a questão problema elaborada em conjunto com a turma; Junção de um grupo de três (03) alunos para construção de um artigo a partir da convergência dos textos elaborados individualmente.

O desenvolvimento das atividades oportunizou a turma do $8^{\circ}$ período (semestre) do Curso de Pedagogia, composta por 29 alunos, destes, 27 do sexo feminino e dois (02) do sexo masculino se depararem com situações reais da sociedade contemporânea.

A metodologia de análise adotada é a descritiva. Segundo Medeiros (2014), essa maneira de analisar os resultados é a ideal para um estudo exploratório, pois permite refletir os dados coletados sob a luz do referencial utilizado.

\section{Resultados e discussões}

Na primeira aula, foi apresentado um relato de caso (fictício). Os alunos realizaram a leitura e em seguida foi solicitado que fizessem apontamentos sobre os problemas destacados no referido relato. As primeiras impressões sobre a realidade vivenciada pelas pessoas surdas foram sendo alocadas na sala de aula. Algumas discordâncias também ocorreram. Diante do turbilhão de dúvidas e algumas verdades consideradas impostergáveis, a docente solicitou que os alunos realizassem a leitura de dois (02) textos diferentes sobre a temática "Surdos e a Educação Inclusiva". 
Os alunos foram divididos em dois grupos e estes discutiram, emitiram suas opiniões e percepções, além de expor dúvidas. Em seguida os grupos foram desfeitos e houve a socialização em grande grupo. Umas das implicações desse primeiro momento foram as divergências de opiniões e a falta de apropriação sobre a proposta que a educação inclusiva preconiza referente a pessoa surda; apesar dos textos estudados a priori conterem informações dessa natureza.

Diante do exposto anteriormente, algumas dúvidas foram surgindo por parte da docente, a exemplo: Como trabalhar o referido conteúdo de modo a articular pressupostos teóricos com a realidade observada no sistema educacional? De que modo propiciar uma construção congruente que possibilitasse consistência teórica e permitisse uma problematização que gerasse reflexões sobre o estudo pretendido e os objetivos propostos?

Nesse momento, o aporte teórico da acerca da estratégia utilizada permitiu uma minimização das angústias iniciais. Acerca da aprendizagem baseada em problemas Gil (2012, p. 175) explica que:

[...] é uma aprendizagem em que os estudantes trabaIham com o objetivo de solucionar um problema. Trata-se, portanto, de uma estratégia de ensino centrada no estudante, que deixa o papel de receptor passivo e assume o papel de agente e principal responsável pelo seu aprendizado.

Assim, o aluno é instigado a pensar sobre a problemática proposta e posteriormente buscar uma resposta, tendo como base discussões pertinentes à sociedade. Araújo e Sastre (2009) descortinam que o uso de questões atuais, problemas vivenciados em sociedade, tidos como apontamentos relevantes e que carecem de soluções, são excelentes fontes para que esse tipo de estratégia seja aplicada, visto que colocam o aluno como protagonista do processo, levando a tomar uma posição mais proativa. Corroborando com o exposto acima, Ott (2010, p. 68) acredita que por meio da solução de problemas, o aluno é incumbido de "[...] aprender a ver a realidade" e nesse processo e instigado a "[...] descobrir aqueles problemas que incomodam a população e que, gradativamente, pelo conhecimento e sentimento, deverão também incomodar o aluno".

A partir deste embasamento, o próximo passo, foi usufruir do momento inicial, em que as divergências foram marcantes e aprofundar 
as discussões, permitindo que os alunos manifestassem suas acepções, conforme conhecimentos prévios, paradigmas científicos, dentre outros, trazendo assim, este sujeito para o centro do processo.

De modo que, ao sentirem segurança de seu papel no processo orquestrado, tiveram a liberdade de pontuar tópicos, tais como: A educação inclusiva está apenas no papel; A sociedade é preconceituosa sobre a condição linguística da pessoa surda; Há a necessidade de aprender de modo significativo sobre a pessoa surda; $\mathrm{O}$ surdo deveria aprender separadamente dos ouvintes; dentre outros. Com a mediação docente, com a utilização de bases teóricas e experiências que se remetiam à temática, algumas dúvidas e verdades até o momento consideradas incontestáveis foram sendo (des)construídas, e novas apreensões foram sendo forjadas. No decorrer desse processo que ocorreu paulatinamente, a questão problema foi tomada forma.

Ao final da etapa descrita anteriormente houve a elaboração do questionamento que seria elemento norteador para que os alunos realizassem a problematização e buscassem uma solução sobre o problema emergido. Para tanto, estes realizariam a construção de um texto dissertativo, com embasamentos teóricos que sustentassem suas acepções.

A segunda aula foi destinada à construção do texto. Os alunos individualmente realizaram suas produções. Retomando a fala de Gil (2008), o aluno nesse tipo de estratégia assume seu protagonismo, sendo o responsável pelo seu aprendizado. Nessa perspectiva, seguiu-se a elaboração dos textos. A professora serviu apenas como mediadora para eventuais dúvidas que ocorressem. Sobre essa característica, Masetto (2012) enfoca que o profissional que antes era um especialista no laboro de transmitir o conhecimento, passou a ser um mediador de aprendizagem.

O próximo encontro da disciplina foi crucial. Neste, os alunos foram novamente convidados a se unir em grupo. Agora composto por três (03) alunos cada. A proposta era acoplar cada um dos textos de modo que se concatenassem e se transformassem em um artigo científico. Algumas renúncias deveriam ser feitas, a escolha dos parágrafos mais coerentes que convergissem com as ideias dos demais autores do grupo, foi bem complexa para os alunos. O fato de não terem familiaridade com a estratégia, fez emergir alguns questionamentos, tais como: Professora, creio que isso não dará certo; Não imagino como minhas ideias e escritos irão se interligar ao demais e se transformar em um artigo; 
Enfim, perguntas que levaram mais uma vez a docente a retomar os aportes teóricos que sustentam a relevância do planejamento para o desenrolar de atividades como esta. Aqui os dizeres de Delors (2006, p. 157) se entrelaçam com a prática docente, visto que "O trabalho do professor não consiste simplesmente em transmitir informações ou conhecimentos, mas em apresentá-los sob a forma de problemas a resolver". Nesse sentido, o próprio exercício reflexivo sobre as potencialidades e resultados da estratégia se encaixa com o propósito de tornar o aluno o agente de suas construções e consequentemente o professor um mediador.

Ademais, Arão e Chaves (2013), confirmam que estratégias desse tipo promovem a reflexão, a análise sobre situações reais, além de promoverem a proatividade, que é um exercício que envolve reflexão e ação sobre a tomada de decisões em grupo. Assim estas têm como escopo:

[...] preparar o aluno para a busca, seleção, integração e emprego das informações científicas atualizadas na área para a solução de problemas; atuar em equipe com entusiasmo e envolvimento nas atividades propostas e nas tarefas a serem cumpridas [...] (ARÃO; CHAVES, 2013, p. 37).

No enfretamento desse exercício, os alunos passaram a atuar em equipe e realizaram a congruência entre os textos para a criação do artigo que contemplasse o questionamento inicial e tivesse indicadores de possíveis soluções para a problemática levantada.

Levando em consideração que este processo demanda algumas posturas por parte dos alunos, como "participar ativamente de discussão, demonstrando a capacidade de questionar, propor ideias e ouvir o que cada colega tem a dizer" (ARÃO; CHAVES, 2013, p. 137), além de ponderar sobre o que deve ou não compor o trabalho de forma coletiva, a próxima aula serviu para os alunos mais vez se reunissem e conseguissem arrematar suas ideias sobre os construtos do artigo. Convém enfatizar que o tempo para o desenvolvimento da parte final da estratégia, se deve pelo fato do público escolhido que realizou a atividade, são alunos/ trabalhadores, que em sua maioria não tem disponibilidade de se reunir extraclasse.

A última aula teve como objetivo a entrega do artigo, digitado e impresso. Ainda, nesse momento, os grupos destacaram as problemá- 
ticas mais especificas que decidiram abordar; e relataram que possíveis soluções seriam viáveis para minimizar ou até sanar o problema exposto. A docente teve a oportunidade de colher algumas impressões sobre $o$ processo vivenciado pelos acadêmicos por meio da estratégia "Aprendizagem baseada em problemas".

No tocante as etapas realizadas, os alunos registraram suas impressões por meio de dois questionamentos, o primeiro foi: Como essa experiência impactou na aprendizagem e construção da autonomia? Foram selecionadas as seguintes respostas: "foi muito importante para a construção da minha autonomia, busquei me apropriar melhor para escrever melhor", "O aprendizado foi notório. Consegui compreender a realidade vivenciada pelos surdos na sociedade atual", "Com essa estratégia pude me debruçar nos textos que antes aguardava o professor explicar" "Esse processo me levou a buscar mais embasamento para conseguir fazer um texto coerente e que conseguisse entender, para mim foi uma construção autônoma e muito significativa".

O segundo questionamento foi: De que forma a problematização auxiliou na compreensão dos conteúdos propostos pela disciplina? alguns alunos registraram que: "Por meio de problemas, o aluno é levado a pensar e repensar situações que até o momento não o instigavam a buscar soluções", "Os problemas destacados nessa estratégia permitiram a análise de situações reais que os surdos passam na escola e na própria sociedade", "permitiu que eu como futura professora racionalizasse que forma poderia sanar ou minimizar a problemática para promover a inclusão verdadeiramente", "Hoje somos constantemente impulsionados a resolver problemas. Assim, a atividade proporcionou na prática o que a sociedade exigirá de nós enquanto profissionais". É relevante pontuar que as respostas foram escolhidas de forma aleatória, o intuito aqui foi perceber se a partir de escolhas assistemáticas apareceriam registros de uma construção significativa pautada na atividade, e se os alunos atingiram a maturidade para compreender tal processo, visto que, para o professor que aplica tal estratégia:

[...] a avaliação se faz naturalmente no contato do aluno com a experiência e na análise que realiza junto com o professor. Nenhum artificialismo precisa ser introduzido, pois em cada etapa o aluno realmente aplica o que recolheu na etapa anterior, não havendo, portanto, a necessidade de interromper a aprendizagem para examinar as condições do aluno (OTT, 2010, p. 74). 
Os resultados foram bem animadores. As respostas ratificaram que o uso da estratégia "Aprendizagem baseada em problemas" podem propiciar construções coerentes. A dialogicidade ocorrida no processo e o aprender a fazer na ação também foram confirmados, evidenciando a compreensão sobre um dos objetivos propostos para a efetivação da estratégia.

Realizar essa atividade foi bastante desafiador para a docente. Após concluído o processo fica claro que uma das implicações para a realização desse tipo de tarefa, é o compromisso que o docente deve ter, realizando um planejamento que deve levar em consideração as peculiaridades da turma, o nível de conhecimento do acadêmicos, e sobretudo, a disposição destes para aceitar o desafio de participar de uma sequência de aulas incomuns para eles.

Outro ponto a ser denotado diz respeito à possibilidade de evidenciar aos acadêmicos em formação que, estratégias diferenciadas podem levar a aprendizagens consistentes, e que o conformismo das aulas meramente expositivas deve ser superado por propostas mais dinâmicas.

\section{Considerações finais}

Ao longo deste artigo foram tratadas algumas questões referentes às práticas pedagógicas e como as escolhas dos docentes podem ou não levar a um processo de construção de conhecimentos consistentes. As estratégias de ensino são consideradas nesse interim como uma ferramenta, que permite ao educador trabalhar de forma diferenciada, conteúdos que corriqueiramente são evidenciados por meio de aulas expositivas. Podendo ser instrumentos instigantes de trabalho que permitirão aos educadores potencializar o processo de aprendizagem dos alunos (TAPIA; MONTERO, 2004).

O estudo realizado permitiu uma reflexão mais aprofundada sobre o trabalho com conteúdos considerados pelos alunos como"enfadonhos", por ter em seu corpus um misto de aspectos históricos e legais e em diferentes momentos, de difícil compreensão. As escolhas pessoais que culminaram nesta atividade foram principalmente referente à contextualização necessária para tratar de uma temática bastante discutida na contemporaneidade, mas que ainda necessita ser problematizada no meio social. 
Foi percebido que os alunos passaram por algumas (des)construções e permitiu que as suas acepções fossem afloradas de forma dinâmica, o que em outros momentos, com outros conteúdos de igual importância, ficou velada. $\mathrm{O}$ envolvimento dos acadêmicos e as construções advindas dos textos também ratificou que houve um maior comprometimento por parte destes em prol de um resultado satisfatório.

Embora, o desenvolvimento da estratégia tenha sido positivo, tanto pelos registros dos alunos após a realização desta, quanto pelo fato das produções apresentarem um rigor teórico bem consistente e uma articulação com a problemática emergida das discussões, reitera-se que outros desdobramentos poderiam ter sido realizados para minimizar algumas situações, em suma, mais textos que explorassem a temática; maior tempo para a exposição das ideias dos alunos, com vistas a proporcionar a mediação da docente e assim sanar algumas concepções errôneas que persistiram até a fase de congruência dos textos e uma explicação mais detalhada acerca da estratégia proposta.

Nas palavras de Pozo, Monereo e Castelló (2004) a explicação do professor mediante a aplicação de qualquer tipo de estratégia é de suma importância, haja vista, o esclarecimento e entendimento por parte do aluno sobre os procedimentos a serem realizados otimizará todo o processo, levando o aluno a uma tomada de consciência sobre seu papel. Assim, um aprofundamento sobre os passos que são inerentes a determinada estratégia, podem potencializar o seu desenvolvimento.

Logo, dada as construções aqui enfatizadas, fica ratificado que o docente deve ser um mediador no processo de aprendizagem de seus alunos e que suas escolhas são indubitáveis para a promoção da eficácia desse processo. Espera-se que este estudo provoque interesse nos leitores, estimulando assim, a realização de outros estudos e ampliação dos espaços de uso e difusão da língua de sinais nas Instituições de Ensino Superior.

\section{Referências}

ARÃO, Luis Carlos. CHAVES, Andréa Carla. Estratégias para o Ensino de Fitoterapia por competências: Cadernos de apoio para professores. Caderno do Programa de Pós-graduação em Ensino de Ciências e Matemática da PUC de Minas. Belo Horizonte: 2013.

ARAÚJO, Ulisses F.; SASTRE, Genoveva (Orgs). Aprendizagem baseada em problemas no ensino superior. São Paulo: Summus, 2009. 
BRASIL. Presidência da República - Casa Civil. Lei no 10.436, de 24 de abril de 2002. Dispõe sobre a Língua Brasileira de Sinais - Libras e dá outras providências. Brasília, 2002. Disponível em: http://www.planalto. gov.br/ccivil_03/leis/2002/L10436.htm. Acesso em 14 out 2017 às 16:05.

BRASIL. Presidência da República - Casa Civil. Legislação - Decreto no 5.626, de 22 de dezembro de 2005. Regulamenta a Lei no 10.436, de 24 de abril de 2002, que dispõe sobre a Língua Brasileira de Sinais Libras, e o art. 18 da Lei no 10.098, de 19 de dezembro de 2000. Brasília, 2005. Disponível em: http://www.planalto.gov.br/ccivil_03/_ato20042006/2005/decreto/d5626.htm. Acesso em 14 out 2017 às 19:01.

CANDAU, Vera Maria (org.). A didática em questão. - 30. ed. - Petrópolis, RJ: vozes, 2010.

DELORS, Jacques. Educação: um tesouro a descobrir. 10. ed. São Paulo: Cortez; Brasília, DF: MEC; UNESCO, 2006.

GIL, Antônio Carlos. Métodos e técnicas de pesquisa social. 5 ed. São Paulo: Atlas, 2007.

. Metodologia do Ensino Superior. São Paulo: Atlas, 2008.

Didática do Ensino Superior. 1 ed. -7 reimpr. São Paulo. Atlas.

2012.

GOBBO, André; BEBER, Bernadette; BONFIGLIO, Simoni Urnau. Metodologias Ativas de Aprendizagem: Uma experiência de qualidade no Ensino Superior de Administração. Educação e Emancipação (UFMA), v. 9, p. 251-276, 2016.

JUSTINO, Marinice Natal. Pesquisa e recursos didáticos na formação e prática docentes. Curitiba: InterSaberes, 2013. (Série Pesquisa e Prática Profissional em Pedagogia).

MACHADO, Lucyenne Matos da Costa Vieira; LíRIO, Larissa Mendonça. A disciplina de Libras e a formação inicial dos professores: experiências dos alunos de graduação em Pedagogia na Universidade Federal do Espírito Santo. Revista FACEVV, v. 1, p. 96-104, 2011.

MASETTO, Marcos Tarcísio. Competência pedagógica do professor universitário. 2. ed. ver. - São Paulo: Summus, 2012.

MEDEIROS, João Bosco. Redação Científica: a prática de fichamentos, resumos e resenhas. 12. ed. São Paulo: Atlas, 2014. 
MEZZARI, Adelina. O Uso da Aprendizagem Baseada em Problemas (ABP) como reforço ao ensino presencial utilizando o ambiente de aprendizagem Moodle. Revista Brasileira de Educação Médica, v. 35, p. 114-121, 2011.

MORIN, Edgar. Os sete saberes necessários à educação do futuro. São Paulo. Ed. Cortez, Brasília, DF: UNESCO, 2004.

OTT, Margot Bertolucci. Ensino por meio de solução de problemas. In: CANDAU, Vera Maria (org.). A didática em questão. 30. ed. Petrópolis, RJ: Vozes, 2010.

PIMENTA, Selma Garrido; ANASTASIOU, Léa das Graças Camargo. Docência no ensino superior. 4. ed. São Paulo: Cortez. 2010 (Coleção Docência em Formação).

PERRENOUD, P. Avaliação: da excelência à regulação das aprendizagens - entre duas lógicas. Porto Alegre: Artmed, 1999.

POZO, Ignacio Juan; MONEREO, Carles; CASTELLÓ, Montserrat. O uso estratégico do conhecimento. In: COLL, César (org). Desenvolvimento psicológico e educação. tradução Fátima Murad. 2. ed. Porto Alegre: Artmed, 2004.

REGO, Tereza Cristina. VYGOTSKY: uma perspectiva histórico-cultural da educação. 10. ed. Vozes. São Paulo: 2000.

RIBEIRO, Luis Roberto de Camargo. Aprendizagem baseada em problemas (PBL) na educação em engenharia. Revista de Ensino de Engenharia, v. 27, p. 23-32, 2008.

TAPIA, Jesús Alonso; MONTERO, Ignacio. Orientação Motivacional e estrátegias motivadoras na aprendizagem escolar. In: COLL, César (org). Desenvolvimento psicológico e educação. Tradução Fátima Murad. 2. ed. Porto Alegre: Artmed, 2004.

TOLEDO JÚNIOR, Antônio Carlos de Castro. et al. Aprendizagem baseada em problemas: uma nova referência para a construção do currículo médico. Revista Médica de Minas Gerais (Belo Horizonte), v. 18, p. 123131, 2008.

Recebido em: março/2018

Aprovado em: setembro/2018 